\title{
Explaining Curriculum Change: Social Studies in Hong Kong
}

\author{
PAUL MORRIS, GERRY MC CLELLAND, AND WONG PING MAN
}

This article traces the emergence and struggle for survival of social studies as a school subject in Hong Kong, paying particular attention to changes in socioeconomic conditions and to the roles played by individuals and groups. Sociological studies on the emergence of school subjects can be categorized in terms of their conceptual underpinnings and level of analysis. School subjects are conceptualized as a product either of functional adjustments within the social system or of social conflict. Alan Dawe describes the origins of these approaches as tied to two sociologies, one concerned primarily with social order and the other with the attempts of individuals to control their destinies. ${ }^{1}$ With regard to the level of analysis, the focus is on micro-level processes or macro-socioeconomic relationships.

At the micro level, detailed historical analyses have focused on shifting amalgamations around subgroups struggling for influence on the curriculum through the acquisition of territory, status, and resources. ${ }^{2}$ Ivor Goodson argues with reference to the emergence and transformation of geography in the United Kingdom, for example, that subject groups tend to move from promoting pedagogic innovation and utilitarian values toward a more academic orientation. As a consequence of the search for higher status, school subjects become increasingly linked to public examinations and tertiary studies. The conflict resulting from attempts by various sectors in society to determine the nature of school subjects has been interpreted primarily from a Marxist perspective (as conflict between social classes) or a Weberian one (as competition between status groups). Success is linked to a group's ability to control or influence variables such as public examinations, teacher associations, and the content of textbooks.

An alternative macro-level view is that the introduction of new school subjects and changes to existing ones are a consequence of functional shifts caused by changing socioeconomic needs and influences within

\footnotetext{
${ }^{1}$ Alan Dawe, "The Two Sociologies," British Journal of Sociology 11, no. 3 (1970): 207-18.

${ }^{2}$ Examples of such studies are Ivor Goodson, School Subjects and Curriculum Change (London: Croom Helm, 1983); Stephen J. Ball, "English for the English since 1906," in Social Histories of the Secondary Curriculum: Subjects for Study, ed. Ivor Goodson (London: Falmer, 1985), pp. 53-58; Mary Waring, "To Make the Mind Strong Rather than to Make It Full: Elementary School Science Teaching in London, 1870-1904," in Goodson, ed., pp. 121-44.
} 
societies. ${ }^{3}$ Malcolm Skilbeck suggests four external or macro-level factors for explaining curriculum change: economic forces, population shifts, changes in sociocultural values, and attitudes toward the school curriculum. ${ }^{4}$ In Hong Kong, macro politics-especially the political relationship between Hong Kong and the People's Republic of China-also have exerted a powerful influence on the curriculum. George Papagiannis interprets curriculum change from a macro perspective as the product of conflict between dominant and subordinate social groups. ${ }^{5}$ From this neo-Marxist perspective the school curriculum is viewed as an instrument of social control, ensuring that innovations that might undermine the status quo are doomed to failure. ${ }^{6}$

From a more recent macro-level perspective, curriculum change is interpreted as subject to "global" influences. Mark Ginsburg and others, for example, combine what they term national-level and world-system explanations to argue that "one cannot adequately understand the dynamics in nation-states or localities without taking into consideration development in the world system." Frederick Wirt and Grant Harman adopt a similar stance when they state that "national qualities ... operate like a prism, refracting and adapting extramural influences, without blocking all of them." 8 This perspective has been extended by studies which argue that American and European educational innovations have set the standard for other nations. Using social science instruction as an example, S. Y. Wong argues that after World War II there was a widespread move away from traditional subjects such as history and geography to social studies. "The dramatic post-World War II worldwide shift from the traditional history and geography content to a new form of integrated subject matter called 'social studies' is a reflection more of a general change in world social patterns than of internal attributes of national societies. This change is also a response to the transformation of structural dominance among hegemonic powers since World War II in that social studies, virtually absent in Eastern European countries, illustrates the extensive influ-

\footnotetext{
${ }^{3}$ Good examples showing the long-term impact of macro-level factors on the emergence and demise of individual school subjects are provided by Christopher A. Stray, "From Monopoly to Marginality: Classics in English Education since 1800," in Goodson, ed., pp. 19-52; June Purvis, "Domestic Subjects since 1870," in Goodson, ed., pp. 165-76.

${ }^{4}$ Malcolm Skilbeck, "Social and Cultural Factors Affecting Curriculum," in The International Encyclopedia of Education: Research and Studies, vol. 8, ed. Torsten Husén (London: Pergamon, 1985), pp. $4608-12$.

${ }^{5}$ George Papagiannis et al., "Toward a Political Economy of Educational Innovation," Review of Educational Research, vol. 52, no. 2 (1.982).

${ }^{6}$ Another example is provided by Rolland G. Paulston, "Cultural Revitalization and Educational Change in Cuba," Comparative Education Review 16, no. 3 (October 1972): 474-85.

7 Mark Ginsburg et al., "National and World-System Explanations of Educational Reforms," Comparative Education Review 34, no. 4 (November 1990); 474-99.

${ }^{8}$ Frederick Wirt and Grant Harman, eds., Education, Recession, and the World Village: A Comparative Political Economy of Education (Philadelphia: Falmer, 1986), p. 4.
} 
ence of the United States in the rest of the world." Similarly, Yun-Kyung Cha argues that changes to foreign language teaching reflect how the emergence of new hegemonic powers in the international system affected which foreign languages predominate in secondary school curricula. ${ }^{10}$

This perspective on curriculum change has many of the features of nineteenth-century diffusion theory, but the transfer of ideas is interpreted as evidence of a form of imitation, dependency, and hegemony. Clearly, certain countries have operated at different times as centers for the diffusion of innovations of all sorts. The ability to identify prevailing curriculum models that transcend national boundaries does not, of itself, explain curriculum change in any particular country. An adequate explanation would need to account for the internal and external motives and pressures for change, as well as the source of the innovations promoted.

The usefulness of these perspectives can be tested against the experience of curriculum change in Hong Kong during the rapid expansion of free and compulsory schooling at the junior secondary level (students approximately $12-15$ years old). As a relatively small society and a British colony (until July 1, 1997), Hong Kong might have been expected to show a high degree of dependency on curriculum trends and developments elsewhere. If ever there were a place where "hegemonic powers" could have a determinative influence on the emergence or adoption of new curricula, it should be Hong Kong.

Our essential argument is that a syncretic explanation is required, one based on an analysis of curriculum change that recognizes the distinction among initiation, design, adoption, and implementation and that also does not uncritically accept the rhetoric of policy statements as evidence of real change. ${ }^{11}$ Each of these phases can be influenced and shaped by a different combination of forces. With regard to the factors affecting the initiation phase, particular reference is made to the role of an insecure colonial government responding to a major socioeconomic shift and to the impact of mass schooling. The design of the Hong Kong curriculum was shaped by the political relationship with the People's Republic of

\footnotetext{
${ }^{9}$ See, e.g., John W. Meyer, David H. Kamens, and Aaron Benavot, eds., School Knowledge for the Masses (London: Falmer, 1992); Aaron Benavot et al., "Knowledge for the Masses: World Models and National Curricula, 1920-1986," American Sociological Review 56 (1991): 85-100; S. Y. Wong, "The Evolution of Social Science Instruction, 1900-86: A Cross-National Study," Sociology of Education 64, no. 1 (January 1991): 33-47.

${ }^{10}$ Yun-Kyung Cha, "Language Instruction in National Curricula, 1850-1986: The Effect of the Global System," in Meyer et al., eds., pp. 84-100.

${ }^{11}$ Some of the data on which this study were based are described in more detail in Paul Morris, "Preparing Pupils as Citizens of the Special Administrative Region of Hong Kong: An Analysis of Curriculum Change and Control during the Transition Period," in Education and Society in Hong Kong, ed. Gerald Postiglione and Leung Yat Ming (Hong Kong: Hong Kong University Press, 1992), pp. 117-45; and Wong Ping Man, "The Evolution of a Secondary School Subject in Hong Kong: The Case of Social Studies" (Ph.D, diss., University of Hong Kong, 1992).
} 
China, by competition among bureaucratic groups, and by societal preferences for English-medium instruction. Its adoption and implementation were determined by the autonomy of schools and a range of pragmatic factors, especially the influence of public assessment in a highly selective and competitive school system.

\section{The Social, Political, and Economic Context of Curriculum Change}

Before World War II, the population of Hong Kong underwent a sort of tidal flow. Workers were attracted from China during good times, and they returned home when economic conditions were bad. The majority were unaccompanied by families. After the resumption of British sovereignty in 1945, the population of about 600,000 experienced similar changes for a few years but then began to be affected by a largely onedirectional flow of refugees from the civil war in China. Unlike the earlier workers, these immigrants included entire families. By 1950 the population was more than 2.2 million and it rose to more than 4.3 million by 1975. After initially treating the newcomers as transients, the government began in the mid-1950s to assume responsibility for them as permanent citizens, with legitimate needs for services such as housing and schooling.

With a burgeoning population of unskilled workers from agricultural communes needing employment, as well as a solid core of seasoned entrepreneurs, combined with minimal government regulation, Hong Kong achieved a dramatic rise in output from labor-intensive industries. The United Nations trade embargo of China and the effects of the Korean War led to an emphasis on manufacturing, and real per-capita income rose about 200 percent between 1950 and 1975 .

Rising standards of living were reflected in rising expectations and demands for schooling from all sectors of the population. They also could be seen in increased government revenues that allowed officials to meet these growing demands. For most, schooling provided the only readily available route to higher social status. A demand for schooling also resulted from the large number of young mothers employed in manufacturing, leading to the rapid expansion of primary education and, in 1971, free and compulsory primary schooling. As demand progressed beyond the primary level, extension of junior secondary schooling by 3 years was proposed in 1974 and achieved in 1979.

Hong Kong has been described as an "administrative no-party state"12 pursuing a policy of "positive non-interventionism."13 Its relationship with China partly explains why a more democratic form of government did

\footnotetext{
${ }^{12}$ Peter Harris, Hong Kong: A Study in Bureaucratic Politics (Hong Kong: Heinemann, 1978).

${ }^{13}$ An expression used by the Financial Secretary of Hong Kong, Sir Philip Haddon Cave, in the mid-1970s.
} 
not develop. Authorities feared that the Chinese Communist Party would object to the introduction of political institutions incompatible with its own and that moves toward self-government would be interpreted-both by the Chinese government and within Hong Kong-as a first step toward political independence. Any moves unacceptable to China would have placed the British administration in jeopardy. ${ }^{14}$

As the economy moved from entrepôt trade to manufacturing, the government's role shifted from relatively passive maintenance of an orderly environment in which a free market could operate effectively to more active intervention. Problems of social injustice including inequitable distribution of wealth and inadequate social welfare provisions could not be solved by laissez-faire methods. Civil disturbances in 1952, 1956, and 1966-67 underscored the government's tenuous legitimacy and made clear the need to provide benefits, predominantly education and housing.

In the absence of party politics and elected representation, the Civil Service - which carried out both executive and legislative tasks-dominated the political system. Recognition of the value of public consultation and participation was sharpened by the $1966-67$ riots. The report on the disturbances stated that "there is a need to develop civic consciousness and a responsibility to Hong Kong; the comparative lack of which may be explained by the absence of a strong feeling of identification. . . . More time could, with advantage, be found also for more instruction in civic education at all stages of school work." 15

While the political system remained top-down and centrist, forms of popular participation began to be encouraged, such as feeding suggestions into the policymaking process and assisting in implementing government policies. This shift was reflected in the changing role of teachers during the 1970s in curriculum development, an area in which their participation previously had been limited to the inclusion of a few token individuals from government schools on textbook and syllabus committees of the Education Department. With the establishment of the Curriculum Development Committee (now Council) in 1972 to advise the Education Department on syllabuses, and the Hong Kong Examinations Authority in 1977 to organize public examinations, more teachers, including those from nongovernment schools, became involved.

Nevertheless, although these changes brought more teachers into the consultative process, they did not represent major shifts in the political culture because committees lacked power to implement decisions. Teach-

\footnotetext{
${ }^{14}$ A full analysis of the nature of and influences on policy making in Hong Kong is provided by Norman Miners, The Government and Politics of Hong Kong (Oxford: Oxford University Press, 1981 ). 1967).

${ }^{15}$ Commission of Inquiry, The Kowloon Disturbances, 1966 (Hong Kong: Government Printer,
} 
ers were recruited to help revise or draft new syllabuses, but the government determined what syllabuses would be considered and maintained the final say on all proposals through a wide range of regulations and ordinances. As an example, schools could legally use only printed resources and syllabuses approved by the director of education, and those who wished to use other materials had to provide full justification. Despite tight government control over curricular content and textbooks, schools could decide the subjects offered and the language of instruction, decisions influenced by public examination results and the selection of pupils. In a society with an extremely uneven distribution of income, access to schooling and subsequent life chances were determined primarily by performance on a series of examinations. The result was intense scholarly competition that promoted the development of a highly academic curriculum and English as the medium of instruction.

By 1973 approximately 55 percent of the urban population was native to Hong Kong. Exposed through education, the media, and contact with international businessmen and tourists to cosmopolitan life-styles and attitudes, the second generation expected higher living standards and a greater scope for individual expression and self-indulgence than their parents had sought for themselves. Accompanying this outlook was a rising awareness of social problems. In 1973, for example, there were 40,000 reported crimes-an increase of 17 percent over the previous year-and property offenses committed by juveniles formed the bulk of these criminal activities. ${ }^{16}$ In response, to ensure that all children below age 15 were in school, the government initiated in 1974 a widespread youth services program that included 9 years of compulsory education. Moreover, the government mandated citizenship training, with a stress on developing a strong sense of belonging, especially at the junior secondary level.

The move to compulsory secondary education also addressed a mismatch between the needs of pupils who would not proceed to tertiary education and labor market requirements. Although 48 percent of school leavers were recruited into industry, only about 4 percent of secondary pupils were enrolled in technical or vocational programs. A narrowly focused academic curriculum geared to producing candidates for whitecollar jobs had failed to meet Hong Kong's manpower requirements.

Compulsory secondary education meant a change in expectations and characteristics of pupils, as secondary schools would no longer deal primarily with highly selected and motivated students. The aims, content, 1973).

${ }^{16}$ Hong Kong Government, The Hong Kong Annual Report (Hong Kong: Government Printer, 
and methods of teaching had to adapt to this reality, and in 1975 the government introduced a new curriculum suitable for all pupils, complete in itself rather than acting as a preparation for further studies and featuring a "common core" curriculum with social studies comprising one of its components.

\section{Schooling in Hong Kong}

Hong Kong's educational system in the mid-1970s was modeled after that in the United Kingdom: 6 years of primary schooling starting at age 6 , up to 7 years at the secondary level, and up to 4 years in tertiary institutions. The secondary curriculum involved three phases: junior secondary, which included forms (corresponding to grades) 1, 2, and 3; senior secondary (forms 4 and 5); and the sixth form, which involved a matriculation course of 1 or 2 years.

Access to the system was elitist and examination driven. Even entrance into good primary schools was determined by a test, and many pupils attended preprimary institutions to prepare. Pupils took another examination to determine their secondary school, and at the end of form 3, 70 percent obtained subsidized places in form 4. Many pupils left school at this stage or transferred to private institutions. At the end of form 5, pupils sat for the all-important Hong Kong Certificate of Education Examination (HKCEE), which determined who could enter the sixth form. For every 1,000 pupils who entered primary school in 1968, 660 took the HKCEE in 1978,130 entered the sixth form, and 22 went to one of the two local universities. Many who graduated from these two institutions found employment in the civil service and as secondary school teachers. In brief, before reaching the university level, pupils faced seven selection examinations or interviews. Few school systems were and are as intensely competitive as Hong Kong's.

Most secondary schools were operated by private profitmaking businessess and charitable bodies or agencies provided with government funds. Indeed, less than 10 percent of students attended schools funded and directly operated by the government. The government's reluctance to expand publicly funded education left much of the demand to be satisfied by the private sector. Privately operated schools could select their pupils and the precise combination of approved subjects to teach. They also were permitted to promote their preferred religious and cultural beliefs (e.g., Catholicism, Buddhism, or Taoism), which were considered to be more accommodating to the colonial regime than the communist schools that flourished in the 1950s and 1960s. In regard specifically to Catholicism, an influx of missionaries from the PRC in the early 1950s created a source of willing providers of education who could undertake 
the task at far less cost than the government. The autonomy given to private schools had a marked impact on the subsequent development of social studies.

\section{Why Social Studies?}

While the arguments for a common core curriculum and for civic education were compatible with the introduction of social studies as a separate subject, they could have been satisfied in other ways. Yet several factors favored social studies over alternatives. Hong Kong schools already had adopted a related subject-first called civics, then economics and public affairs - and curriculum designers were aware of trends elsewhere (particularly in the United Kingdom and the United States) to promote and adopt social studies. The efforts of a local pressure group called the Educators' Social Action Council (ESAC) also played an important role.

Schools in Hong Kong had recognized the desirability of social education for junior secondary pupils before 1975. Usually it was provided through subjects such as history, geography, and religious studies. Sometimes, however, it was presented through civics, a subject with relatively low status that had been introduced following the civil war in China to counter the use of schools by both sides for political propaganda and also to help refugees and their children adjust to life in Hong Kong. From the government's point of view, this meant learning to be law-abiding, politically apathetic, and hard-working participants in an urbanized economy, seeking personal and family advancement. The civics syllabus stressed facts about Hong Kong, the workings of government, and the role of citizens in the community. The underlying themes were apolitical and universalistic in the sense that they studiously avoided issues arising from the local political context. At the same time, this strategy was pursued for explicitly political motives. ${ }^{17}$

In 1965, civics was transformed into economic and public affairs (EPA) to gain acceptance by local and overseas universities. In effect, civics was given a more academic orientation and higher status by merging with an established academic discipline, economics. EPA was not, however, an unqualified success, largely because most teachers assigned to junior secondary forms were not specialists but were drawn from other disciplines, such as Chinese or English. Those who were specialists tended to focus narrowly on the economics component.

\footnotetext{
${ }^{17}$ For a fuller discussion of the impact of politics on schooling in Hong Kong, see Paul Morris and Antony Sweeting, "Education and Politics: The Case of Hong Kong from an Historical Perspective," Oxford Review of Education 17, no. 3 (1991): 249-67; and Antony Sweeting and Paul Morris, "Educational Reform in Post-war Hong Kong: Planning and Crisis Intervention," International Journal of Educational Development 13, no. 3 (1993): 210-16.
} 
The emergence of social studies in Hong Kong during the early 1970s was clearly influenced by developments in British and American social studies education (e.g., the Keele Integrated Studies and the New Social Studies projects) through the training of key personnel and the use of overseas consultants.

The ESAC-consisting of lecturers from the universities and colleges of education, school principals, a principal curriculum development officer, and other government officials - was formed in Hong Kong in 1971 after an international conference in Kyoto on social education provided the inspiration for change. No local teachers were involved. The council argued that citizens unconcerned about their immediate neighbors, people in the region, and the whole world could not be regarded as truly educated. ${ }^{18}$ The ESAC offered practical suggestions to help teachers foster desirable qualities and attitudes in their students, organized workshops and seminars, and published a series of pamphlets. Several of its members were chosen by the government to serve in $1974-75$ on a committee to design a social studies syllabus.

\section{The Process of Development}

The Initial Planning Stage, 1971-73

Although the framework for the social studies syllabus initially was shaped by officials from the Education Department, developments from 1971 to 1973 are difficult to trace due to the government's policy of confidentiality. Overall, consultation was limited and informal and confined to teachers and principals with whom the officials were acquainted. Officials attempted to make the subject integrated and pragmatic, with content derived from economics and public affairs, geography, history, and health education using Hong Kong as the focus. These pioneers placed social studies in line with overseas models, ${ }^{19}$ with their "attention to process (inquiry and discovery), critical thinking ... contemporary issues and relevance."20 Envisaged as a subject taught in Chinese that would embody utilitarian and pedagogical goals, particularly oriented toward less academic pupils, these ideals were not, however, achieved in practice.

The idea of teaching social studies in Chinese was quickly abandoned in the face of implacable opposition from officials concerned about the low status in the local community of subjects taught in that language.

\footnotetext{
${ }^{18}$ Educators' Social Action Council, "Introduction," Pamphlet No. 1 (Hong Kong: Caritas, 1972).

${ }^{19}$ The most influential precedents were Edwin Fenton, The New Social Studies (New York: Holt, Rinehart \& Winston, 1967); and D. W. Oliver and J. P. Shaver, Teaching Public Issues in the High School (Boston: Houghton Mifflin, 1966).

20 Peter Seixas, "Parallel Crises: History and the Social Studies Curriculum in the U.S.A.," Journal of Curriculum Studies 25, no. 3 (1993): 235-50.
} 
Parental choice ensured that most schools pursued an official policy of using English as the medium of instruction. This was a consequence of high returns from English language competency, especially with regard to access to higher education and employment prospects within Hong Kong and elsewhere. This demand for English-medium schooling remains an intractable problem, severely constraining all attempts at curriculum reform.

The idea of an integrated curriculum threatened the position of important groups and therefore also failed to gain support. Inspectors of history, geography, and EPA feared that the introduction of nonacademic material, taught by teachers inappropriately trained, at the junior secondary level would leave pupils unprepared for study in forms 4 and 5. To preserve their status in the face of proposed changes, these inspectors tried to maximize the share of their own subjects in the new syllabus.

The outline syllabus had to be modified many times. By the final version, Chinese history had become a discrete subject, while the remaining subject areas-geography, economics, history, and public affairs - had roughly equal shares of the "territory." The needs of nonacademic pupils, as originally perceived by the curriculum policymakers, had been subordinated to those of more academic pupils as the designers attempted to satisfy the demand from each subject group for adequate linkage to the critical examination syllabus in forms 4 and 5. This, in turn, led to the inclusion of so much material that social studies emerged not as an integrated subject but as an excessively large collection of topics from different subjects. To minimize opposition within the Advisory Inspectorate, no intention was expressed at this stage to extend the curriculum to the senior secondary level.

In 1974, when this process was well advanced, two overseas experts, one from the United Kingdom and the other from Canada, were invited to advise on the introduction of the subject. Their role essentially was to advocate the need for social studies and in so doing to provide greater credibility and respectability to the government's policy. Although some of the idealism had been generated by knowledge of developments elsewhere and some foreign experts were involved in the initiation of the subject, it would be very hard to argue that the influence of structural dominance by hegemonic powers was binding.

\section{The Design Stage}

Plans to introduce social studies were announced at a seminar for junior secondary teachers organized by the Advisory Inspectorate in December 1974. Although participants expressed concern at the lack of real integration in the proposed syllabus, the government concluded that teachers were enthusiastic and that there was no "definite" objection to the idea of social studies as a single subject. 
Following the seminar, a committee consisting of 10 officials (seven Advisory Inspectorate officials, two College of Education lecturers, and one government school principal) and eight other members nominated by the government (two university lecturers, five principals, and one teacher) was formed to draft a full provisional syllabus. The posts of chairman and secretary were filled by officials from the Advisory Inspectorate. Nongovernment members clearly understood their role, as the following remark succinctly illustrates. "I think we had no right to say whether to have a social studies syllabus or not. We were there simply to give our own opinions and suggestions. The presence of unofficial members in the committee was a kind of window dressing."21

In fact, most of the committee's unofficial members claim not to have favored the idea of social studies, although they did not openly oppose it in the group's meetings. They shared earlier concerns about links with established academic subjects in forms 4 and 5 and about the training given to teachers. Timetable arrangements also were viewed as a problem, as social studies had to be taught by instructors from a variety of subjects. In addition, they were uncertain that teachers would be willing to spare extra time for the new subject. One principal suggested that members on the committee did not openly oppose the syllabus because civil servants in Hong Kong during the early 1970s were not as used to accepting or tolerating diverse opinions as they later became. Most of the nongovernment members simply expressed their views without ever insisting on changes or modifications. Principals were well aware that they ultimately could decide whether to adopt social studies in their schools.

Ambiguity of authority over subject matter mirrors the government's countervailing motives for controlling the curriculum. Extensive regulations and ordinances to control the content of subjects and selection of textbooks emerged in the late 1940s to counter the Kuomintang and the Chinese Communist Party, who used school curricula to promote their political ideologies. Although the subjects to be taught and the language of instruction were decided by schools, these decisions were driven by the public examination system and the process of selection to higher levels of education, factors that ensured a highly academic curriculum.

Committee members expressed dismay that the whole idea of integration, which subsequently spread to various levels of schooling, had not been "nipped in the bud" and frustration over the haste with which the proposal was pushed through. Only 4 months separated the formation of the working party and completion of the provisional syllabus. Overall, government officials played the most significant role in developing social

\footnotetext{
${ }^{21}$ Interview with a secondary school principal, Qctober 1991.
} 
studies. Spurred by the initiative of the principal curriculum development officer, Advisory Inspectorate officials guided the curriculum's development.

The subject that emerged was an amalgam of topics that included health and welfare, the individual and society, population, living patterns in Hong Kong, urbanization, pollution and conservation, education, Hong Kong's neighbors, industrialization, law and order, the structure of Hong Kong's industrial economy, and work and leisure. More specifically, social studies offered an extensive description of the workings of various government departments (e.g., Health and Housing, and Education) and the services they offered, along with an apolitical, decontextualized, and abstract promotion of the characteristics and responsibilities of a good citizen. ${ }^{22}$ Under the topic the "individual and society," for example, the specified content included all of the following: development of individual personalities, living together (families and social groups), human relationships (friendships), cooperation and interdependence, social and emotional problems of adolescence, the role of citizens, the individual and the state (ideas of citizenship in ancient Rome and Greece, public life in Greek city states, the Roman Republic, the expansion of Rome, and Greek and Roman influence on modern legal and political systems), other forms of government, and religion and society. Pupils also were to study a theme called "living in Hong Kong," which included a brief history, the geographical setting, communication, clothing (national costumes), food, housing, types of transport, traditions and customs, urban land use, pollution and conservation, education, and the economy. With regard to law and order, students examined the workings of the civil service, the legal system, and problems in this area. When issues such as pollution or crime were included, they were identified and then followed by a description of the government measures taken to solve them. The only reference to the PRC is in the context of identifying Hong Kong's geographical neighbors and the operation of communes, while no mention is made of concepts such as democracy, elections, public participation, or Hong Kong's colonial status.

\section{Dissemination and Adoption, 1975 to the Present}

The provisional syllabus was promoted and disseminated through circulars and seminars, the classic tools of an administrative strategy for curriculum development. Thirteen schools were recruited to pilot the

\footnotetext{
22 These characteristics were not confined to social studies. Other subjects-especially Chinese language, literature, and history - had an abstract and classical orientation. See, e.g., Bernard $\mathbf{H}$. K. Luk, "Chinese Culture in the Hong Kong Curriculum," Comparative Education Review 35, no. 4 (November 1991): 650-68.
} 
provisional syllabus and another 17 schools volunteered to adopt it on a trial basis. The Education Department carried out an evaluation from 1976 to 1978 , but the results remain confidential. In 1979 the provisional syllabus became permanent, with no more than minor cosmetic changes. ${ }^{23}$

In support of the new subject, Hong Kong's three colleges of education devoted greater attention to social studies and two of them introduced special courses in 1975 for students' final year of study. Instigated by the Education Department, a few energetic young teachers established the Hong Kong Association for Social Studies in 1979. This association promoted social studies in forms $1-3$ by publishing a newsletter, designing teaching kits, and arranging seminars, workshops, and trips.

Despite these developments and its intended status as a core subject, social studies was not popular. Only about a third of schools had adopted the subject by 1985 , and that proportion had dropped to less than a quarter by 1990. Most schools continued to offer economic and public affairs, history, and geography as independent courses, and some schools that initially had introduced social studies withdrew it after a few years.

According to principals and teachers, its failure to gain popularity at the secondary level stemmed from its inability to conform with actual conditions in schools. Obstacles to its implementation partly arose from poor design, as the content of the syllabus was perceived as unnecessarily long and fragmented, while the recommendations regarding structural and pedagogical changes turned out to be impractical. Specifically, the use of team teaching, double periods, outside visits, and outside speakers were perceived as dysfunctional given constraints on scheduling and resources. Moreover, without being an examined subject at the form 4 and 5 levels, it is not surprising that social studies eventually was rejected in many of the schools that originally had adopted it. ${ }^{24}$ In addition, the Hong Kong Association for Social Studies became inactive in 1981-82 as many of the founders lost interest in teaching, others changed jobs or even left Hong Kong, and some were promoted. The chairman, for example, became principal of a school and turned his attention to his own administrative work rather than to the promotion of social studies. Further, the establishment of the permanent syllabus in 1979 reduced the perceived need for advocacy.

${ }^{23}$ Soon after, extension of social studies to make it a subject in forms 4 and 5 was proposed, making it an examinable subject in the critical Hong Kong Certificate of Education Examination. The syllabus for the subject at this level was developed through a similar process and was first publicly examined in 1986. A major aim was to achieve a higher level of adoption of the forms 1-3 syllabus by establishing a link to a subject at forms 4 and 5 , but in this it was not successful.

${ }^{24} \mathrm{~J}$. A. Gerry McClelland, "Curriculum Development in Hong Kong," in Curriculum Development in East Asia, ed. C. Marsh and Paul Morris (London: Falmer, 1991). 


\section{The New Social Studies}

In 1984, after 2 years of negotiations, the British and Chinese governments agreed that Hong Kong will cease to be a British colony in 1997 and will become a special administrative region under Chinese sovereignty. Although the Sino-British Joint Declaration calls for the maintenance of the status quo in Hong Kong for 50 years, the "1997" issue has dominated public debate since the early 1980s, with Hong Kong residents becoming increasingly concerned about their future. The impending return of Hong Kong to Chinese sovereignty has placed a premium on ensuring a graceful exit by the British, and this is manifested in a curriculum more oriented toward China. To prepare pupils for their future as citizens of the PRC, a new set of moral education/civic education guidelines was introduced. Government and public affairs became a new subject at forms 4 and 5 in 1988, and the content of various subjects-including economic and public affairs, Chinese history, history, and geography-changed markedly after 1984 to promote pupils' understanding of Chinese processes and culture..$^{25}$ The content of the social studies curriculum in forms 1-3 also radically changed, most notably by featuring topics about China and promoting affiliation to Chinese culture generally and the PRC specifically. By having students draw the PRC flag; describe the development, structure, and workings of the Chinese Communist Party; study the biography of Mao; and understand the need for central planning, the revised syllabus is an about-face on content deemed acceptable in Hong Kong schools. Prior to $1982-84$, such activities would have been viewed as contrary to Education Regulation no. 98 ("activities of a party political nature") and would have resulted in the closure of schools, the dismissal of teachers, and the withdrawal of government financial support. Given the changed political structure, however, social studies has been revised so that pupils are prepared for their future as citizens of China. Moreover, the new social studies has introduced a number of topics that have the potential to increase pupils' awareness of current political issues, including Hong Kong's status as a special administrative region, the 1984 joint declaration, and representative democracy as a feature of political development and Hong Kong's future. Clearly, what constitutes acceptable curriculum content has changed in response to shifts in the political context of Hong Kong.

\section{Conclusion}

The introduction of social studies was one part of the government's response to shifting socioeconomic conditions, most notably an influx of

\footnotetext{
${ }^{25}$ For a fuller discussion of the impact of 1997 on the school curriculum, see Paul Morris, Curriculum Development in Hong Kong, Education Paper no. 7, The University of Hong Kong (Hong Kong: Faculty of Education, 1990).
} 
refugees from the PRC and the emergence of an increasingly youthful population-one whose low level of commitment to Hong Kong threatened the stability and tenuous legitimacy of a colonial government. Extended schooling and a curriculum designed to serve the majority provided a means for incorporating refugees and reducing the potential for social conflict. Social studies was to be a centerpiece of these efforts at political socialization. Its introduction underlined the government's response to a range of emerging social issues, including the state's need to preserve itself. Because the colonial government required a subject that encouraged civic responsibility and political acquiescence, the social studies curriculum provided pupils with a positive portrayal of the government, offered a decontextualized and apolitical view of responsible citizenship, and avoided reference to the contemporary culture and politics of the PRC. At the same time, however, societal expectations reinforced an exam-driven school system that placed a premium on instruction in English, a condition that eroded the stature of a subject designed originally to meet the needs of less able students. The effect of these influences was to transform social studies from an inquiry-oriented, integrated subject aimed largely at nonacademic pupils into an interdisciplinary, fragmented set of largely descriptive topics oriented toward later academic study. As such, it bore little resemblance to its namesakes in the United States and United Kingdom. ${ }^{26}$

When the need to address the long-term survival of the colonial government was removed by the 1984 agreement to return sovereignty of Hong Kong to the PRC, priorities shifted to ensure short-term stability and a graceful exit by the colonial powers. School curricula were reoriented to prepare pupils for their future as PRC citizens. This included, in 1989 , a radical reorientation of social studies, which shifted from an apolitical and decontextualized focus to one that provided pupils with an understanding of the PRC's political institutions and culture. In effect, the political parameters that had influenced the design of the subject in the 1970 s were reversed in the 1980 s, and this was reflected in changes to the nature of the subject. Clearly, the political relationship between the PRC and the United Kingdom has been binding.

26 The context and motives for the introduction of social studies in Hong Kong parallel those associated with its introduction specifically and mass schooling generally in the United States and elsewhere. An analysis of the different conceptions of and roles played by social studies is provided by R. D. Barr, J. L. Barth, and S. S. Sherms, Defining the Social Studies (Arlington, Va.: National Council for the Social Studies, 1977). A contemporary argument for social studies as a vehicle for cultural transmission is provided by Lynne Cheney, American Memory: A Report on the Humanities in the Nation's Public Schools (Washington, D.C.: National Endowment for the Humanities, 1987). A detailed historical analysis of the rise of mass education and its link to the rise of the nation-state in the United States, the United Kingdom, and France is provided by Andy Green, Education and State Formation (London: Macmillan, 1990). 
The key decisions as to whether a school would adopt social studies and, if so, how it would be taught were based on a range of essentially pragmatic considerations. Central among these was the lack of a direct linkage to subjects on the all-important HKCEE. Officials at most schools believed that pupils studying social studies would be at a disadvantage during forms 4 and 5 if that subject displaced traditional academic subjects-specifically history and geography-in forms 1-3.

Many schools that adopted social studies subsequently dropped it as expectations for the subject were not compatible with the resources available and the way education was organized. ${ }^{27}$ The low initial level of adoption and the even lower level of follow-through present an apparent paradox. On the one hand, the colonial government provided free and compulsory schooling, within which it included social education. On the other hand, it permitted the intended syllabus to be distorted beyond recognition and gave schools complete freedom to adopt or reject it. The government, however, had little choice. Having tenuous legitimacy, it could not present a benevolent image as provider of a social goodextended schooling - and at the same time heavy-handedly impose a syllabus in a way that would have conflicted with that image. Provided that a syllabus did not encourage views hostile to the government, there was no need to intervene. Similar ambivalence was displayed with regard to the policy and practice toward the language of instruction. For nearly $3 \mathrm{dec}-$ ades the government promoted the use of Chinese but allowed schools to decide their own policy on this matter. Because English has a much higher status, the Hong Kong government felt unable to implement a policy of instruction in Chinese that would have been unpopular and contrary to market forces. Moreover, the use of English did not pose a direct threat to the government. ${ }^{28}$

There can be no dispute that the development of social studies in other countries, particularly the United Kingdom and the United States, influenced the curriculum in Hong Kong, especially at the policy and

\footnotetext{
${ }^{27}$ As David Hamilton observed, "The introduction of integrated studies is not merely equivalent to introducing a new syllabus but implies a radical change of emphasis in the organizational content and thinking of secondary education," ("The Integration of Knowledge: Practice and Problems," Jourmal of Curriculum Studies 5, no. 2 [1973]: 70-81). It also has been suggested that a major public confrontation between school authorities and pupils (the Precious Blood Golden Jubilee Incident) in 1977 contributed to the subject's demise. Principals became cautious of a subject that might encourage pupils to question and criticize the organization and structure of the school itself. This concern is a reflection of the sensitivity during this period of educators to the possibility of politics entering the classroom. In itself, the content of the social studies curriculum was distinctly devoid of issues and politics. See Choi Po King, Sociological Observations on Education (Hong Kong: Wide Angle Press, 1987).

${ }_{28}$ For a fuller discussion of curriculum policies in Hong Kong, see Paul Morris, The School Curriculum in Hong Kong: Development, Policies and Isswes, 2d ed. (Hong Kong: Hong Kong University Press, 1995).
} 
initiation stages. Nevertheless, the emergence of social studies in Hong Kong cannot be adequately explained simply by the influence of external models. Although these models provided a rhetoric for change that enthused pioneers and policymakers as well as exemplary material and a means for justifying policies, they were modified beyond recognition in the design and adaptation of social studies to the local environment.

Clearly it is necessary to ensure that explanations focusing on policy reforms are distinguished from those focusing on practice. Thus, S. Y. Wong's view that other countries have adopted exemplary social science syllabuses from the United States without regard to local conditions, ${ }^{29}$ and Mark Ginsburg's argument that local conditions merely serve to refine global influences, are insufficient to explain the case of social studies in Hong Kong. ${ }^{30}$ The existence and diffusion of social studies there can be taken as valid evidence neither of the demise of traditional subjects nor of a "worldwide hegemony throughout the modern period."

Overall, our study has demonstrated that, at a macro level, socioeconomic developments can create the preconditions for curriculum change, within parameters set by political realities, especially a government's instinct of self-preservation. Worldwide trends can provide both rhetoric and models for specific sorts of policy changes. At a micro level, however, conflict or competition among subgroups can modify or transform proposed changes, and the adoption and implementation of the changes are determined by a range of pragmatic considerations within schools. ${ }^{31}$

\footnotetext{
${ }^{29}$ Wong (n. 9 above).

${ }^{30}$ Ginsburg et al. (n. 7 above).

31 This article has focused solely on the case of a single subject in Hong Kong and some features of that society - such as its colonial status and the absence of a mandated national curriculum - might be viewed as limiting the potential generalizability. However, a survey of curricular policies in East Asian societies suggests that the prevailing political tensions in each country have exerted a powerful influence on the nature of the content of those schools subjects that can influence national identity, such as history, geography, social studies, civics, or their equivalents. The nature of these tensions and their impact on the school curriculum is discussed more fully in Marsh and Morris, eds.
} 